\title{
ASSESING THE BUCHAREST'S PUBLIC TRANSPORT NETWORK BY USING THE QUALITY FUNCTION DEPLOYMENT TOOL
}

\author{
Ruxandra DINULESCU \\ The Bucharest University of Economic Studies, Bucharest, Romania \\ ruxandra.dinulescu@man.ase.ro \\ Alexandru-Mihai BUGHEANU \\ The Bucharest University of Economic Studies, Bucharest, Romania \\ mihai.bugheanu@man.ase.ro \\ Adina-Liliana PRIOTEASA \\ The Bucharest University of Economic Studies, Bucharest, Romania \\ prioteasaadina@gmail.com
}

\begin{abstract}
The Bucharest public transport networks need to establish innovative strategies in order to improve their overall service quality.

Therefore, in order to accomplish this objective, the current study will evaluate public transport customer demands applying the Quality Function Deployment (QFD).

Furthermore, the research aims to highlight user requirements and to evaluate an appropriate strategy to improve the current public transport services.

Thus, for determining the users' satisfaction, a survey with a sample of 175 respondents was carried out, and the outcomes of the survey were used as input data for defining the QFD method.

The objective of this paper is to present the public bus transport users' demands, as well as alternatives to improve the main weakness noticed in the bus transportation system. In addition, the article will present a short review of the literature and the research methodology for the QFD.

The key findings of this study will focus on presenting, based on the QFD methodology, the main projects that need to be started, in order to improve a part of the main users' dissatisfaction regarding the public bus network.

Keywords: Bucharest, public transport, Quality Function Deployment, urban mobility.
\end{abstract}

\section{INTRODUCTION}

The world is at a stage of a modern transport revolution. New technologies and innovations are widely used to transform the current industry and to accelerate the service improvements.

With this in mind, nowadays collective transport systems highly influence the quality of life throughout the world. 
Starting with the responsibility of being the dominant mode of transport, together with having an extensive impact on quality of life this type of transit is by definition used globally by millions of individuals in every city. It is often overlooked, but the public transport sector is also one of the biggest employers at European level, as well as large contributor for the economy.

As a result, determining the fundamental attributes for user's satisfaction represents the starting point for any research that aims to improve the service quality. In the same time, when analysing the transport process the user is both the recipient of the service as well as the judge.

To put it differently, public transportation is a social phenomenon in every modern society. Specifically, the average number of trips for the $28 \mathrm{EU}$ Member States exceeds 60 billion journeys per year. In particular, in Romania the overall demand for public transport decreased while the number of journeys in Bucharest increases every year (International Association of Public Transport, 2016).

The current study is part of an extensive research on the public transport networks in Bucharest, and their influence upon users' quality perception.

Therefore, this paper will focus on evaluating the main topics that affect the customers in Bucharest, and for that we will use a survey based method: the Quality function deployment.

Subsequently, we will present a potential strategy or method that could positively influence the public transportation services.

In the long run, our main objective is to design several alternatives that could be successfully implemented by the public transport operators or authorities in Bucharest in order to improve the service quality.

Given these points, the public transportation system will be analysed by using the quality function deployment tool, a method aimed for satisfying users' needs and requirements, by promoting a proactive attitude towards quality issues, rather than a reactive position regarding the users' complaints (Dobrin \& Dinulescu, 2019).

\section{LITERATURE REVIEW - AN OVERVIEW PRESENTATION OF THE QUALITY FUNCTION DEPLOYMENT TOOL}

One of the main objectives of the QFD method is to ease the possibility to achieve an equitable balance between passengers' requirements and the means' of transport ability to obtain those requirements. Thus, the QFD tool is also recognized as a decision making technique that supports adopting complex decisions regarding the transportation system (Burke, 2002).

Specialized literature works in the field of public transportation are abundant nowadays due to its significant impact on the quality of life for EU citizens. Due to its clarity and ease of use and the Quality function deployment (QFD) has been broadly studied and used in applications related to collective 
transportation. As a result, a substantial amount of research has been published in the topic of QFD technique applications in transport.

On the other hand, evaluating the satisfaction level or perceptions in the public transport networks is an elaborate and difficult process. Specifically, various authors, such as (Beirao \& Cabral, 2007), (Nathanail, 2008), (Iseki \& Taylor, 2010), (Eboli \& GabriellaMazzulla, 2011), (Colesca, Pacesila, Burcea, Ciocoiu, \& Bugheanu, 2017) proposed different approaches on measuring the quality and satisfaction on metropolitan regions of the European Union. Usually the researchers adopt a ranking system for every quality attribute. Nevertheless, these characteristics are susceptible to numerous changes depending on social and economic factors.

As an illustration, (Bajcetic, Tica, Zivanovic, \& Branko Milovanovic*, 2018) presented a case study on the QFD technique in order to identify collective transport passengers necessities and requirements, as well as methods to improve the service quality. The research was carried out in Serbia, Belgrade, using a survey of 15000 urban public users. As a result, a correlation between passengers, requirements and the activities of the transport network was established. Furthermore, $55.61 \%$ of the respondents considered regularity and vehicle comfort as unsatisfactory. On the other hand, regarding potential aspects that may be improved in the future by the service providers, respondents stated that vehicle frequency, staff behavior and vehicle equipment could significantly increase the users' satisfaction level.

Also in the public transportation field, (Bilişik, Şeker, Aydın, Güngör, \& Baraçlı, 2019) analyzed passenger satisfaction using the Fuzzy-QFD methodology in order to reduce the users' complaints towards service quality. The case study was developed on the public transport network in Turkey, Istanbul and drew conclusions on integrating passengers' requirements into the process of efficient and qualitative collective transport.

According to Sivaloganathan (1997), the main characteristics of the QFD technique are the following, presented in Figure 1: 




Source: adapted by authors after Sivaloganathan (1997)

Studies related to the public transportation system have shown that QFD refers to quality as meeting the passengers' requirements. Hence, taking into account the principle of deployment, service quality presents a direct correlation with the quality of the subsystems, which can be settled through the quality of the parts, and in the end, the quality of the parts can be assured through the quality of the process elements (Akao, 1990).

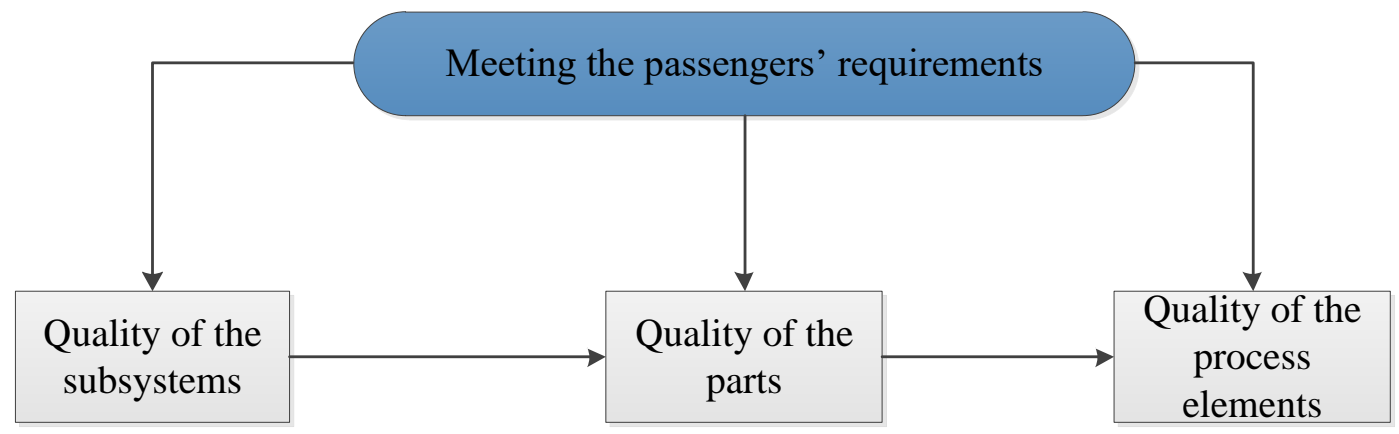

FIGURE 2. QUALITY PERCEIVED FROM THE PASSENGERS' POINT OF VIEW

Source: adapted by authors after Akao (1990)

Before moving on with the research methodology, it is necessary to shortly present the QFD mechanism. The visual representation of the tool, the basic matrix, is known as the house of quality (HoQ). This matrix includes seven blocks of information, each of them representing a different view of the development process, as presented below in Figure 3: 


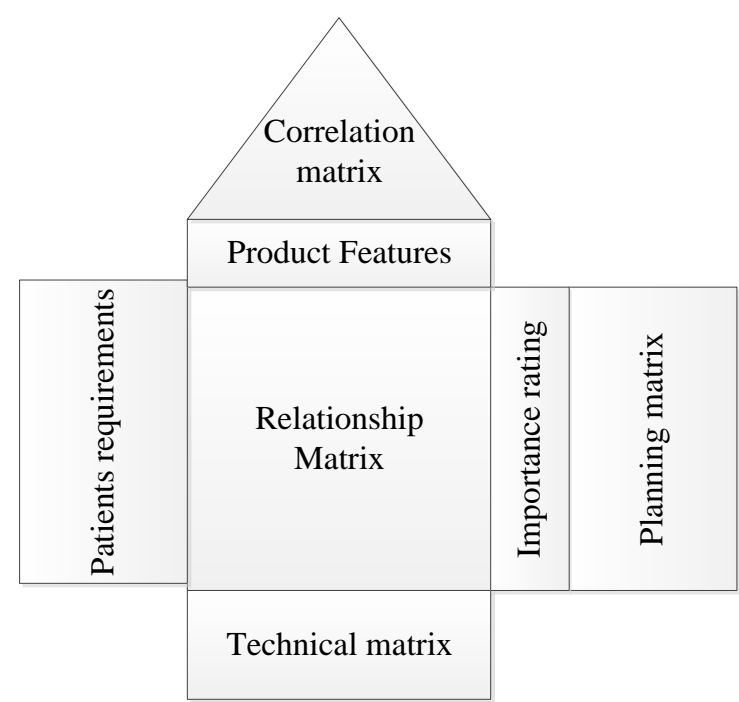

FIGURE 3. HOUSE OF QUALITY

Source: Authors' representation

With the help of these matrices, the cross-functional team is capable of gaining the VoP (voice of the passenger) and thus, to approximate the service design.

For easing the explanations, as well as the entire process, the following stages were considered when applying the QFD method:

$\checkmark$ Stage 1 - capturing the $\operatorname{VoP}$ (using online surveys, questionnaires, interviews);

$\checkmark$ Stage 2 - rating each item's importance (on a scale of 1 to 5 );

$\checkmark$ Stage 3-brainstorming for settling the technical characteristics of the service in correlation to the passengers' requirements;

$\checkmark$ Stage 4 -interpreting the correlations between passengers' requirements and service features ( 0 - no correlation; 1-little correlation; 3-medium correlation; 9-strong correlation);

$\checkmark$ Stage 5 - rating the factors' absolute and relative importance.

Public transportation is an essential activity for any developed and modern society. Therefore, it is mandatory to pay attention to passengers' expectations in order to ensure a quality public transportation services. As a result, public transport networks could become in the future the first option for every user, in terms of modes of transport.

\section{RESEARCH METHODOLOGY}

The current study was conducted from the Bucharest's passengers' public transportation system point of view, by analysing various issued. Thus, the first step consisted of gathering the answers from a sample of 175 respondents, on a two month period, between 01.11.2019-01.01.2020. 

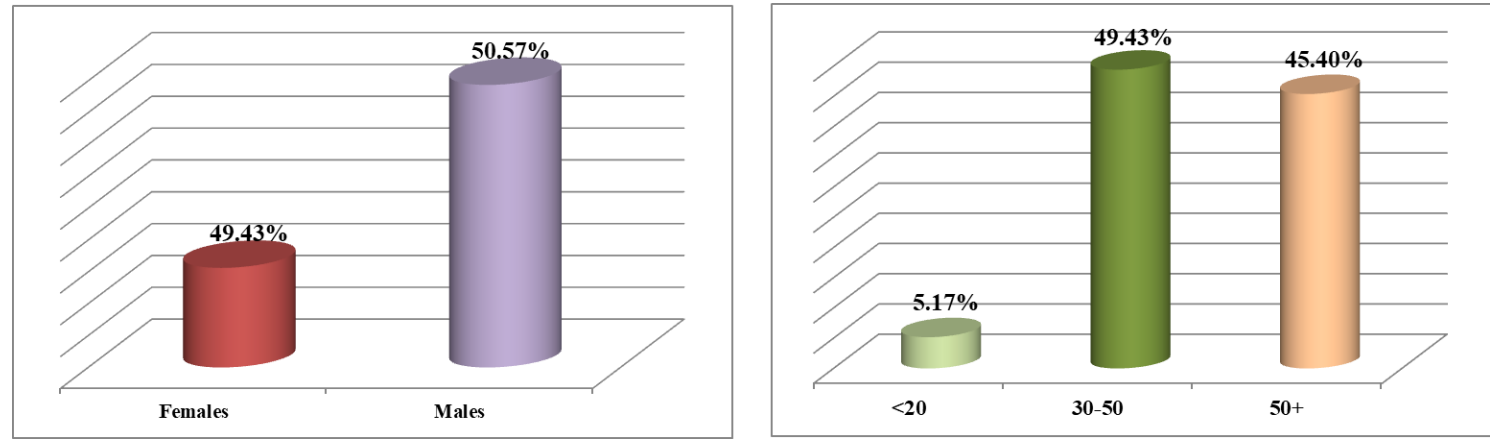

FIGURE 4. SAMPLE' REPARTITION AND AGE INTERVAL

Source: Authors' computations

All the passengers were asked to address their main complaints regarding the Bucharest public transportation network, and then for each attribute, to offer a score of importance on a scale from 1 to 5 ( 1 being least important, while 5 , the most important).

In the second step, after the passengers' answers were registered their opinions were analyzed. Thus, a dedicated group was organized (with different specializations related to the public transport network), having as main objective capturing the passengers' requirements as well as the stakeholders' needs.

In the third step, the correlation between passengers' requirements and the experts' suggestions was established. Also, this stage has a significant importance by implementing the basis of quality improvement initiatives (Chan and $\mathrm{Wu}, 2005$ ).

The fourth step computes the absolute importance by multiplying the importance score of passengers' requirements with cross-relationships between passengers' requirements and service requirements (defined by the team experts).

Therefore, in the current model, another matrix shows the importance for the user (marked with P1), the service evaluation (the importance given by the experts for a certain attribute) and the planned quality (P2- the level which public transport specialists want to achieve after applying the improvement plans).

For determining the absolute weight (absolute importance P1) of factors, the following computation has been used (Eq. 1):

Absolute importance $(\mathrm{P} 1)=$ User requirment1 $\mathrm{x}$ Importance1 for user + User requirment2 $\mathrm{x}$ Importance2 for user $+\ldots .+$ User requirement $x$ Importance for user

Similar calculations have been used for P2. The results are presented in Figure 5 : 


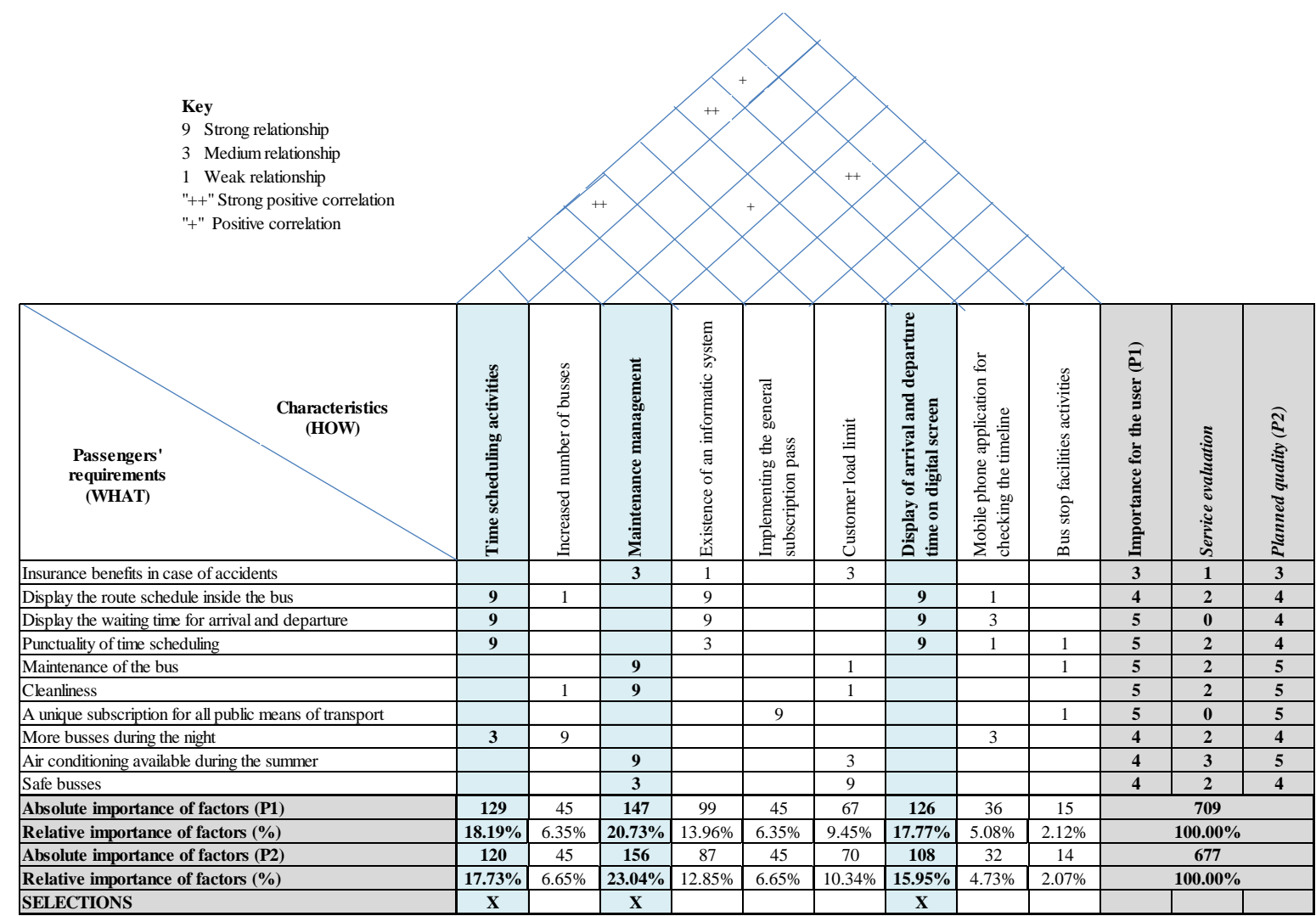

FIGURE 5. QUALITY FUNCTION DEPLOYMENT APPLIED TO THE BUCHAREST'S PUBLIC TRANSPORT NETWORK

Source: Authors' computations

\section{RESULTS AND DISCUSSION}

The above figure collects the passengers' requirements and transforms them into technical attributes, taking into consideration the public transport specialists' initiatives.

Accordingly, in the fifth step, analysing the absolute and relative importance of the factors, ended up by presenting a selection list which included the main directions (based on the highest score) for improving the Bucharest public bus network.

Therefore, the three main projects resulted from the QFD method are:

* Time scheduling activities (including the proper display of the bus schedule, punctuality of the bus, etc);

* Maintenance management (including the degree of cleanliness, the existence of an inside acclimatization, etc);

* The existence of digital screens in the bus stations (announcing delays, time of arrival, time of departure, etc). 
The current study represents an on-going research, hence the QFD method is only an incipient phase of an extensive improvement project. The technique presents a framework with the main passengers' dissatisfaction, as well as, various solutions for how these issues could be solved.

In response, the QFD methodology represents a starting point for the authorities, in order to better understand passengers' needs and to be able to add or change some of the public bus transport's features for being able to create a value added for its users.

\section{CONCLUSIONS}

At the present time, the transport revolution and modern technology affects and influence us all. In the long run, it will revise and even change the manner we travel, along with improving our quality of life.

With this in mind, the current study presents the assessment of the public transportation network in Bucharest using the QFD method. This approach was preferred because the QFD tool has been demonstrated as a useful technique in evaluating service quality features.

At the same time, this paper is part of an ongoing research on Romania's Capital public transport network. In particular, the research aim is to identify various deficiencies in terms of service quality, as well as risks that could occur during traveling. Nevertheless, an important part is also analysing potential measures to reduce the risks and to improve the users' satisfaction.

Point often overlooked, the research literature in the topic of Quality function deployment in the field of transportation in Romania is minimal.

Under these circumstances, researching the effectiveness of the current transportation systems could have long-term positive effects.

Developing quality tools and applying them to the Bucharest public bus network would eventually define what matters the most for the passengers (by listening to the voice of the passenger) and also, will allow the public authorities to create value for users by offering them high quality services, as well as determining a direction for future improvement plans.

All things considered, the research is still at an early stage. Nonetheless, we consider that evaluating several methods and tools to improve the quality of a public service is a necessity in any modern society. In conclusion, governments, public transport authorities or businesses operators need to recognize the potential advantages that modern technologies have to offer. In a word, policy makers have to start planning and adopt strategies for the future. 


\section{ACKNOWLEDGEMENT}

"This study was conducted through the post-doctoral advanced research studies for the academic years 2018-2020, 2019-2021, and doctoral studies 2017-2020, Management field, coordinator The Bucharest University of Economic Studies".

Furthermore, this work was cofinanced from the European Social Fund through Operational Programme Human Capital 2014-2020, project number POCU/380/6/13/125015 "Development of entrepreneurial skills for doctoral students and postdoctoral researchers in the field of economic sciences".

\section{REFERENCES}

Akao, Y. (1990). QFD: Integrating Customer Requirements into Product Design, Productivity Press, Portland

Bajcetic, S., Tica, S., Zivanovic, P., \& Branko Milovanovic*, A. D. (2018). Analysis of public transport users' satisfaction using quality function deployment: Belgrade case study. Transport, 33(3), pp. 609618

Beirao, G., Cabral, S. (2007). Understanding attitudes towards public transport and private car: A qualitative study. Transport Policy, pp. 478-488

Bilişik, Ö. N., Şeker, Ş., Aydın, N., Güngör, N., \& Baraçlı, H. (2019). Passenger Satisfaction Evaluation of Public Transportation in Istanbul by Using Fuzzy Quality Function Deployment Methodology. Arabian Journal for Science and Engineering, 44(3), pp. 2811-2824

Burke, E., Kloeber, JM. Jr, Deckro, R. (2002). Using and abusing QFD scores. Quality Engineering. 15(1):9-21. doi:10.1081/QEN-120006707

Chan, L.K., Wu, M.L. (2005). A systematic approach to quality function deployment with a full illustrative example. Omega, Vol. 33 №. 2, pp. 119-139

Colesca, S. E., Pacesila, M., Burcea, S. G., Ciocoiu, C. N., \& Bugheanu, M. (2017). Analysis of Passenger's Satisfaction with the Quality of the Public Transportation Mode Choices in Bucharest: A Fuzzy Approach. Economic computation and economic cybernetics studies and research, 51(4), pp. 109-125

Dobrin, D., Dinulescu, R. (2018). Integrating the Quality Function Deployment to the Romanian Healthcare System as part of a Continuous Improvement Process. The 34th IBIMA Conference. Madrid, Spain

Eboli, L., Gabriella, M. (2011). A methodology for evaluating transit service quality based on subjective and objective measures from the passenger's point of view. Transport Policy 
International Association of Public Transport. (2016). Local public transport in the European Union. Brussels, Belgium : UITP-Advancing Public Transport

Iseki, H., Taylor, B. D. (2010). Style versus Service? An Analysis of User Perceptions of Transit Stops and Stations. Journal of Public Transportation, 13

Nathanail, E. (2008). Measuring the quality of service for passengers on the Hellenic railways. Transportation Research, Part A

Rao, K. C., Thakar, G. (2013). Enhancement of Customer Satisfaction by QFD in Bus Service. International Journal on Advanced Computer Theory and Engineering (IJACTE), 2(5)

Sivaloganathan, S., Evbuomwan, N. F. O., (1997). Quality Function Deployment- TheTechnique: State of the Art and Future Directions. Concurrent Engineering: Research and Applications, 5 June. 171-181 